OPEN ACCESS

Edited by:

Akio Adachi,

Tokushima University, Japan

Reviewed by:

Karen Dawn Weynberg,

The University of Queensland,

Australia

Shoko Ueki,

Okayama University, Japan

Fumito Maruyama,

Kyoto University, Japan

Miguel Frada,

Weizmann Institute of Science, Israe

*Correspondence:

Steven W. Wilhelm wilhelm@utk.edu

Specialty section:

This article was submitted to

Virology,

a section of the journal

Frontiers in Microbiology

Received: 29 January 2018 Accepted: 03 April 2018

Published: 19 April 2018

Citation:

Moniruzzaman M, Gann ER and Wilhelm SW (2018) Infection by

a Giant Virus (AaV) Induces

Widespread Physiological Reprogramming in Aureococcus anophagefferens CCMP1984 -

A Harmful Bloom Algae.

Front. Microbiol. 9:752.

doi: 10.3389/fmicb.2018.00752

\section{Infection by a Giant Virus (AaV) Induces Widespread Physiological Reprogramming in Aureococcus anophagefferens CCMP1984 - A Harmful Bloom Algae}

\author{
Mohammad Moniruzzaman ${ }^{1,2}$, Eric R. Gann ${ }^{1}$ and Steven W. Wilhelm ${ }^{1 *}$ \\ ${ }^{1}$ Department of Microbiology, The University of Tennessee, Knoxville, Knoxville, TN, United States, ${ }^{2}$ Monterey Bay Aquarium \\ Research Institute (MBARI), Moss Landing, CA, United States
}

While viruses with distinct phylogenetic origins and different nucleic acid types can infect and lyse eukaryotic phytoplankton, "giant" dsDNA viruses have been found to be associated with important ecological processes, including the collapse of algal blooms. However, the molecular aspects of giant virus-host interactions remain largely unknown. Aureococcus anophagefferens virus (AaV), a giant virus in the Mimiviridae clade, is known to play a critical role in regulating the fate of brown tide blooms caused by the pelagophyte Aureococcus anophagefferens. To understand the physiological response of $A$. anophagefferens CCMP1984 upon AaV infection, we studied the transcriptomic landscape of this host-virus pair over an entire infection cycle using a RNA-sequencing approach. A massive transcriptional response of the host was evident as early as 5 min post-infection, with modulation of specific processes likely related to both host defense mechanism(s) and viral takeover of the cell. Infected Aureococcus showed a relative suppression of host-cell transcripts associated with photosynthesis, cytoskeleton formation, fatty acid, and carbohydrate biosynthesis. In contrast, host cell processes related to protein synthesis, polyamine biosynthesis, cellular respiration, transcription, and RNA processing were overrepresented compared to the healthy cultures at different stages of the infection cycle. A large number of redox active hostselenoproteins were overexpressed, which suggested that viral replication and assembly progresses in a highly oxidative environment. The majority (99.2\%) of annotated AaV genes were expressed at some point during the infection cycle and demonstrated a clear temporal-expression pattern and an increasing relative expression for the majority of the genes through the time course. We detected a putative early promoter motif for AaV, which was highly similar to the early promoter elements of two other Mimiviridae members, indicating some degree of evolutionary conservation of gene regulation within this clade. This large-scale transcriptome study provides insights into the Aureococcus cells infected by a giant virus and establishes a foundation to test hypotheses regarding metabolic and regulatory processes critical for AaV and other Mimiviridae members.

Keywords: host-virus interaction, transcriptional profiles, Mimiviridae, algal viruses, brown tide 


\section{INTRODUCTION}

Viruses are thought to lyse cells and release cellular organic and inorganic nutrients that either become available for microbial growth or are exported to the deep ocean (Wilhelm and Suttle, 1999). With an estimated $10^{31}$ virus particles in the sea (Angly et al., 2005), the geographical scale and impact of these processes are enormous - viral activity can turn over an estimate of 150 gigatons of carbon per year (Suttle, 2007). To accomplish this, it has been historically thought that viruses encode a minimal amount of genomic information that instructs host cells to produce new virus particles. Using almost entirely the host machineries, hundreds of virus particles can be produced from one host cell. As an example, Hepatitis B virus encodes only four overlapping genes in a 3.2-kb genome (Liang, 2009), whereas several Picornavirales members, which are widespread in the ocean, only code for one or two proteins (Lang et al., 2009).

This paradigm has been challenged by discovery of "giant" eukaryotic viruses - viruses that rival bacterial cells in terms of their physical size and genomic content (Raoult et al., 2004; Moniruzzaman et al., 2014; Wilhelm et al., 2016, 2017). Phylogenetic analyses of members of this group (known collectively as nucleocytoplasmic large DNA viruses, NCLDVs) (Iyer et al., 2001) have revealed that a major portion of the genomic content of these giant viruses has been acquired from the eukaryotic hosts and other sources through horizontal gene transfer (HGT), some of which are passed vertically through the course of viral evolution (Filee et al., 2007; Koonin and Yutin, 2010; Moniruzzaman et al., 2014). This genomic complement renders these viruses more autonomous from the host cell, empowering them to control individual processes in the complex eukaryotic cells and produce virus-specific macromolecules (Wilson et al., 2005; Claverie and Abergel, 2010).

Giant viruses are thought to play important roles in constraining photosynthetic protists in both marine and freshwater ecosystems (Short, 2012; Moniruzzaman et al., 2017). And while there is growing information regarding large virus diversity, seasonality, and roles in host dynamics, there is a dearth of information regarding the molecular underpinnings of conversion of a healthy host cell into a virus producing "machine" (aka the "virocell") (Forterre, 2011). For example, molecular information is necessary to understand how viral infection can select for resistance in hosts, or shape the macromolecules released during cell lysis into surrounding waters. Indeed, given that infection is an ongoing and prevalent process in the oceans, a significant amount of the particulate chemistry that oceanographers measure may be due to infection phenotypes. Understanding the molecular aspects of giant virus infections can also reveal important markers of infection that can be used to track and differentiate infected cells from healthy cells in situ.

Giant viruses infecting eukaryotic algae are functionally diverse, although they do share a few core proteins (Yutin et al., 2009). As a consequence, significant differences in the molecular basis of interactions can be expected between different eukaryotic host-virus pairs, although not much is known in this regard. High-throughput techniques, like transcriptomics and/or metabolomics, have only been focused on a few ecologically relevant host-virus systems. From the work that exists we know that giant viruses genes, like those from Mimivirus and Paramecium bursaria Chlorella virus1 (PBCV-1), are expressed quickly upon infection: PBCV-1 gene transcripts have been detected within $7 \mathrm{~min}$ of infection (Blanc et al., 2014). These viruses are also known to capture genes through HGT from their hosts and diverse sources, although function of these genes (and even if they are transcribed) remains largely unknown. Critical insights have been obtained regarding the modulation of cellular processes of Emiliania huxleyi - the most abundant coccolithophore alga in the world's ocean - upon infection by large Emiliania huxleyi virus (EhV) (Vardi et al., 2012). This includes virusmediated regulation of the host's lipid biosynthesis resulting in programmed cell death and modulation of the host redox state during infection (Vardi et al., 2009; Rosenwasser et al., 2016). In Mimivirus, elaborate virus factories - cytoplasmic sites for virus replication and assembly - have been detected. Despite these important discoveries, a significant knowledge gap exists regarding the physiological response of a host to a giant virus infection.

Aureococcus anophagefferens is a bloom forming pelagophyte which causes recurrent brown tides along the east coast (Gobler et al., 2005). A giant virus (AaV) was isolated during a brown tide event and shown to infect and lyse Aureococcus in culture (Rowe et al., 2008). A subsequent genomic study revealed the "chimeric" nature of AaV; which picked up large number of genes from diverse cellular sources (Moniruzzaman et al., 2014), while statistical analysis of metatranscriptomic data from a brown tide bloom demonstrated active infection of Aureococcus by $\mathrm{AaV}$ during the peak of the bloom (Moniruzzaman et al., 2017). In addition, $\mathrm{AaV}$ is one of the few algae infecting viruses in the Mimiviridae, a clade of giant viruses that infect both photosynthetic and heterotrophic protists (Moniruzzaman et al., 2014). The availability of genome sequences for both $\mathrm{AaV}$ and its host (Gobler et al., 2011; Moniruzzaman et al., 2014) and recurrent brown tide blooms (Gastrich et al., 2004; Gobler et al., 2007) makes this host-virus pair an interesting model system. No information is available on the progressive changes in the molecular processes of Aureococcus cells upon infection, which might provide critical insights on the metabolic pathways and cellular components that can impact virus production. Moreover, the possible roles and activity of the large number of xenologs that $\mathrm{AaV}$ has acquired from its host, other organisms, and its NCLDV ancestor remain to be elucidated.

In this study, we employed transcriptomics to resolve the molecular response of $A$. anophagefferens to infection by $\mathrm{AaV}$. Our experimental design examined the transcriptomic landscape throughout the $\mathrm{AaV}$ infection cycle to capture the host cellular response and viral transcriptional landscape. This study also provides insight into the molecular interaction between a giant algal virus in the Mimiviridae clade and its host. 


\section{MATERIALS AND METHODS}

\section{Experimental Setup}

Aureococcus anophagefferens CCMP 1984 was maintained in modified L-1 medium (Hallegraeff et al., 2003) at an irradiation level of $100 \mu \mathrm{mol}$ photons $\mathrm{m}^{-2} \mathrm{~s}^{-1}$ and a temperature of $19^{\circ} \mathrm{C}$ for a 14:10 (h) light-dark cycle. Prior to the experiment, Aureococcus cultures were grown to a mid-log phase concentration of $\sim 1.95 \times 10^{6}$ cells $/ \mathrm{ml}$. Five biological replicates $(2.01)$ of Aureococcus cultures at a concentration of $7.5 \times 10^{5}$ cells $/ \mathrm{ml}$ were started within $2 \mathrm{~h}$ of the onset of the light cycle. The cultures were inoculated with $\mathrm{AaV}$ at a particle multiplicity of infection (pMOI) of $\sim 18$. pMOI of 18 was chosen because it led to $\sim 98 \%$ reduction of cell numbers $48 \mathrm{~h}$ post-infection in assays conducted in-house. Due to the absence of a plaque assay to determine infectious units for $\mathrm{AaV}$, we defined pMOI as total virus particles (not plaque forming units) counted using fluorescence microscopy for our experiment. For each biological replicate, control cultures were inoculated with the same volume of a heat-killed viral lysate. The heat-killed lysate was generated by exposure to microwaves (1000 Watts, 120 Volts) (Keller et al., 1988) for $5 \mathrm{~min}$. Molecular aspects that define the different stages (early, intermediate, and late) of $\mathrm{AaV}$ infection are largely unknown. However, it is known that $\mathrm{AaV}$ has an approximately $24 \mathrm{~h}$ infection cycle (Brown and Bidle, 2014). Therefore, samples for sequencing were collected at $5 \mathrm{~min}, 30 \mathrm{~min}, 1 \mathrm{~h}, 6 \mathrm{~h}$, $12 \mathrm{~h}$, and $21 \mathrm{~h}$ after inoculation to capture a range of infection states before lysis (Brown and Bidle, 2014). Specifically, the first three time points were targeted to capture the cellular and viral gene expression changes that unfold within an hour of the infection, whereas the last time point was picked to investigate the events prior to cell lysis. In addition, the intermediate time points (6 and $12 \mathrm{~h}$ ) were included to investigate how gene expression pattern changed as the cycle progressed from initial infection toward cell lysis. For RNA extraction, $250 \mathrm{ml}$ subsamples were filtered through $0.8-\mu \mathrm{M}$ pore-size ATTP filters (EMD Millipore, Darmstadt, Germany) to trap the algal cells. The filters were immediately flash frozen in liquid nitrogen prior to storage at $-80^{\circ} \mathrm{C}$. Unfiltered samples (for cell enumeration) and samples passed through $0.45-\mu \mathrm{m}$ polyvinylidene fluoride syringe filters (Merck, Darmstadt, Germany) for free virus count were preserved in $0.5 \%$ glutaraldehyde at $-80^{\circ} \mathrm{C}$ from each sample at each time point.

\section{Cell and Free Virus Density Estimates}

Aureococcus cells were enumerated using a GUAVA-HT6 flow cytometer (EMD Millipore, Darmstadt, Germany) gated on the red chlorophyll fluorescence. Cell numbers were estimated from running the flow cytometer for $80 \mathrm{~s}$ or 5000 events per sample. Free virus particle densities from each time point was determined following Ortmann and Suttle (2009). Samples were thawed at room temperature and diluted 100-fold using L-1 medium prior to counting. The diluted samples were collected on 25mm diameter Whatman Anodisc (Sigma-Aldrich, St. Louis, MO, United States) inorganic membrane filters having a nominal pore-size of $0.02 \mu \mathrm{m}$. The filters were allowed to air-dry for
15 min following incubation with $15 \mu$ l of $4000 \times$ diluted SYBER Green (Lonza, Rockland, ME, United States). The filters were then fixed using an anti-fade solution (50:50 PBS/glycerol and $0.1 \%$ p-phenylenediamine) (Noble and Fuhrman, 1998). Slides were observed through a Leica DM5500 B microscope at $1000 \times$ magnification with a L5 filter cube (excitation filter: 480/40, suppression filter: BP 527/30) (Leica Microsystems CMS GmbH, Hesse, Germany). For each sample, 20 random fields (1 $\mu \mathrm{m}$ by $1 \mu \mathrm{m}$ ) or 200 particles were enumerated and averaged. The following formula was used to estimate the VLPs/ml in each sample:

$$
\mathrm{VLPs} / \mathrm{ml}=V_{\mathrm{f}} * \frac{A_{\mathrm{a}}}{A_{\mathrm{g}} * V_{\mathrm{f}}} * D
$$

where $V_{\mathrm{f}}$ average virus count/field, $A_{\mathrm{a}}$ total filterable area of Anodisc (excluding the O-ring), $A_{\mathrm{g}}$ area of eyepiece grid, $V_{\mathrm{f}}$ volume filtered $(\mathrm{ml})$, and $D$ dilution factor.

\section{RNA Extraction and Sequencing}

Three biological replicate experiments were used for RNA extraction and analyses at each time point. RNA was extracted with MO BIO PowerWater RNA Isolation Kit [MO BIO Laboratories (now QIAGEN), Carlsbad, CA, United States] following a 2-min bead beating step using Lysing Matrix E $2 \mathrm{~mL}$ tubes (MP Biomedicals, Santa Ana, CA, United States). The manufacturer's protocol was followed with slight modification: specifically, the DNAse treatment step was performed twice to ensure sufficient purity of the RNA. RNA was quantified using a Nanodrop ND-1000 Spectrophotometer (Thermo Scientific, Waltham, MA, United States) and RNA integrity was checked with an Agilent Bioanalyzer 2100 (Agilent Technologies, Santa Clara, CA, United States). Extracted RNA was processed and sequenced at the Hudson Alpha Genomic Services Lab (Huntsville, AL, United States). RNA samples were poly-A selected to enrich for mRNA and deplete ribosomal RNA transcripts. Samples were sequenced using an Illumina ${ }^{\circledR} \mathrm{NextSeq}^{\circledR}$ sequencer targeting approximately 25 million single-end reads per sample and a 76-bp read length. Standard protocols by Illumina ${ }^{\circledR}$ were followed for library preparation, poly-dT bead selection, and sequencing. Sequence data have been deposited in the NCBI short-read archive under bioproject PRJNA432024.

\section{Bioinformatics and Statistical Analysis}

Sequencing reads were initially trimmed in CLC Genomics Workbench 9.0 (Qiagen, Hilden, Germany). Reads with a quality score cut-off of $\leq 0.03$, or with ambiguous bases ("N"s), were discarded. Reads passing quality control were mapped to the Aureococcus (NCBI Accession No. ACJI00000000) and $\mathrm{AaV}$ genome sequence (NCBI Accession No. NC_024697) with stringent mapping criteria (95\% similarity, 70\% length matching). Differential expression of genes in the virus-treated samples compared to the controls was determined at each time point using edgeR (Robinson et al., 2010) program implemented in the CLC Genomics Workbench 9.0. P-values were adjusted for false discovery rate (FDR) using BenjaminiHochberg (BH) procedure (Benjamini and Hochberg, 1995). 
Heatmaps representing data from these analyses (Figures 5, 6 and Supplementary Figures 7, 9, 10) were constructed using statistical computing environment R (R Core Team, 2013). The number of reads mapped to each $\mathrm{AaV}$ gene was rarefied by library size. Values from biological replicates at each time point were averaged prior to hierarchical clustering of the viral gene expression. Figure 2A summarizing this data was constructed using BRIG software (Alikhan et al., 2011). The putative early promoter motif of AaV was detected using MEME (Bailey et al., $2009)$ in discriminative mode. The $E$-values associated with the discovered motifs are a conservative estimate of the number of motifs having equal or higher log-likelihood ratio if the target sequences were randomly generated (Bailey and Elkan, 1994) given a background model.

Functional enrichment within the framework of Gene Ontology (GO) terms (positive or negative fold changes) was determined using BiNGO (Maere et al., 2005). GO enrichment for differentially expressed genes is complicated by at an arbitrary fold-change cut-off imposed prior to the enrichment analysis, which excludes the genes with fold-change values even marginally similar to that cut-off. To partially alleviate this problem, we ran the enrichment analysis on gene sets selected using two absolute fold-change cut-offs: $>1.5$ and $>1.3$. Using both these cut-offs recovered mostly same GO processes; however, some of the processes were missed by each of the individual approaches. Since our analysis is largely exploratory, results obtained from both cut-off were investigated for interesting GO processes. We report all the GO terms recovered by this approach in Supplementary Dataset 1. The up- or down-regulation of KEGG pathway-related gene expression was determined using $z$-test as implemented in "GAGE" $\mathrm{R}$ package (Luo et al., 2009). This analysis employed input from all the genes, irrespective of foldchange level or statistical significance, and looked for coordinated expression changes within a particular pathway. The resulting $P$-values for both the analyses were corrected for FDR using $\mathrm{BH}$ procedure (Benjamini and Hochberg, 1995). We considered a FDR-corrected $P$-value $\leq 0.1$ to be significant for both GO and KEGG pathway enrichment. Heatmaps showing the presence or absence of significantly enriched GO processes (Figure 4 and Supplementary Figure 6) were constructed in statistical computing environment $\mathrm{R}$ ( $\mathrm{R}$ Core Team, 2013). nMDS and clustering analysis of the virus and host gene expression data and associated figure construction were done using the statistical program PRIMER v6.0 (Clarke, 1993).

\section{RESULTS}

\section{Cell Growth Dynamics and RNA-Seq Output}

Cultures inoculated with heat-killed lysates displayed growth patterns similar to a healthy Aureococcus culture, reaching a cell density of approximately $\sim 1.1 \times 10^{6}$ cells/ml by $24 \mathrm{~h}$ (Figure 1 and Supplementary Figure 1). In contrast, the virus-infected cultures didn't show any significant increase in cell density over the course of infection, indicating that a proportion of cells were infected during the first cycle of virus propagation. Consistent

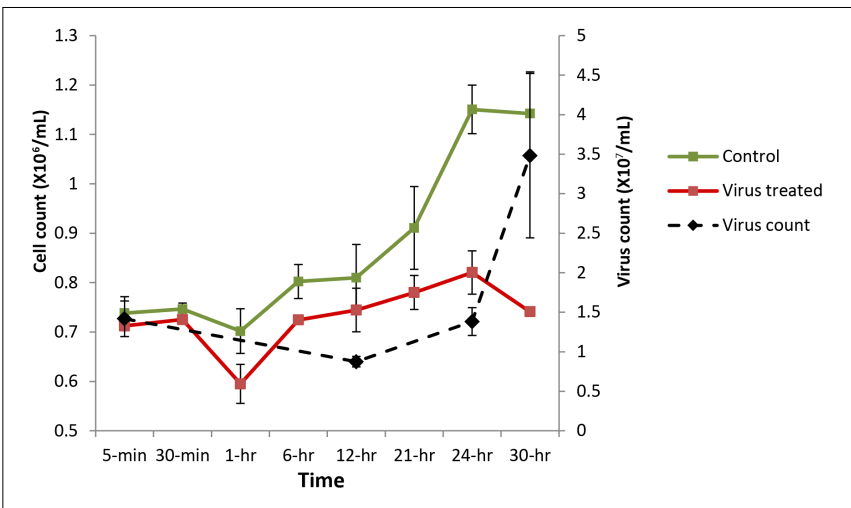

FIGURE 1 | Aureococcus and AaV count over the course of infection. Cell counts are average of three biological replicates, while virus counts are average of two biological replicates. Green, cell count in control cultures; red, cell counts in infected cultures; and black, virus counts.

with previous studies, free-virus titer increased around $24 \mathrm{~h}$ after infection and steadily increased up to $\sim 3.5 \times 10^{7} \mathrm{VLPs} / \mathrm{ml}$ by $30 \mathrm{~h}$ post-infection (Figure 1). Flow cytogram of infected culture shows distinct signature for cells going through lysis - with a subpopulation of cells having lower red fluorescence along with the population of uninfected cells (Supplementary Figure 2). Complete lysis of the culture usually takes $48-72 \mathrm{~h}$ during routine virus production in lab, encompassing two to three infection cycles, in agreement with the results reported previously (Rowe et al., 2008).

After quality trimming, between $\sim 18.2$ and 29.4 million reads were obtained from each of the 36 samples. In the control samples, $\sim 80 \%$ of the reads could be mapped to the host nuclear (NCBI Accession No. ACJI00000000) (Gobler et al., 2011), chloroplast (Accession No. GQ231541) (Ong et al., 2010), and draft mitochondrial genome (scaffold 85 of Aureococcus genome project ${ }^{1}$ ) (Supplementary Table 1). Less than $1 \%$ reads mapped to chloroplast and mitochondrial genome across all samples (Supplementary Table 1). Such lower number of reads captured from organelles is possibly due to different dynamics of polyadenylation in the organelles compared to the nuclear genome. In eukaryotic nuclear transcripts, polyadenylation is an important step for mRNA maturation. However, polyadenylation of organelle and bacterial transcripts leads to their degradation (Chang and Tong, 2012). In the virus-treated samples, the proportion of virus transcripts steadily increased over time (Supplementary Table 1 and Supplementary Figure 3). Aureococcus culture used for this experiment was not axenic. About $\sim 20 \%$ of the reads from all the samples could not be aligned to the host or viral genomes, which likely originated from incomplete parts of the host genome, and/or polyadenylated transcripts from bacteria.

\section{Gene Expression Dynamics of AaV}

Transcripts from 116 viral genes were present in the infected culture as early as 5 min post-infection (Supplementary Table 2

${ }^{1}$ http://genome.jgi-psf.org/Auran1/Auran1.home.html 


\section{A}

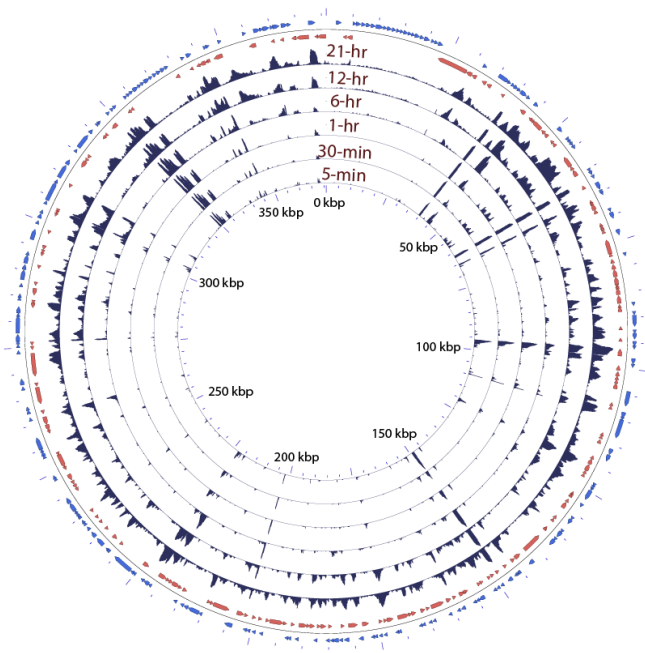

B

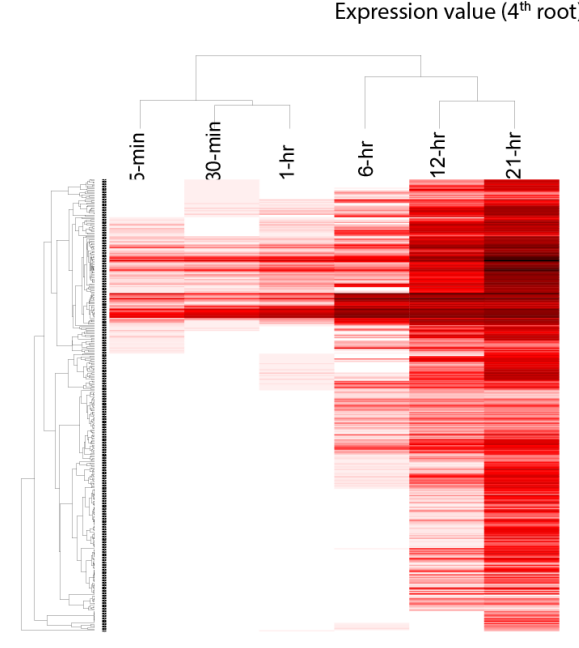

FIGURE 2 | (A) Trend in expression of individual AaV genes over time. The read mapping from each time point was converted to coverage graphs with a 100 bp sliding window. Three replicates from each time points were averaged after rarefaction by library size. The two outermost rings represent the forward (blue) and reverse (red) coding sequences. (B) Heatmap showing temporal pattern of expression of clusters of AaV genes. The read mapping data over individual genes was hierarchically clustered after fourth root transformation.

and Supplementary Figure 3). While only $\sim 0.007 \%$ of the reads could be mapped to viral genome from sequence libraries at $5 \mathrm{~min}, \sim 15 \%$ of the reads originated from viral transcripts by the $21 \mathrm{~h}$ time point (Figure 2A and Supplementary Figure 3). We also observed a high coefficient of variation within replicates for the samples from the first three time points (Supplementary Figure 3). To resolve temporal patterns of virus gene expression, we performed a hierarchical clustering using the average number of rarefied reads per library that mapped to viral genes over the time course. Clear temporal patterns in gene expression were observed, with some genes expressed either immediately or within $1 \mathrm{~h}$ of infection, while reads from other genes appeared later into the infection (Figure 2B). Although the length of $\mathrm{AaV}$ infection cycle is known, data on the specific length of early or late infection stages are not available. Also, even though the first three samples were collected within an hour, there was a large interval between the third (1-h) and fourth (6-h) samples. So, it is possible that expression of any early genes within that interval could only be observed at 6 -h time point. Therefore, we checked the genes expressed within the first four time points together for enrichment of possibly early promoter motifs on their upstream sequences. MEME (Bailey et al., 2009) was used in the discriminative mode to detect. A motif with the general pattern "[AT][AT][AT][TA]AAAAATGAT[ATG][AG][AC]AAA[AT]" was found to be enriched in the gene set expressed within $6 \mathrm{~h}$ with an $E$-value of $2.1 \mathrm{e}-151$, compared to the genes expressed during the last two time points (Supplementary Figure 4A). This motif encompasses the octamer "AAAAATGA." When we searched for the AaV-specific octamer motif, we found that $47.5 \%$ (127 genes) of the genes expressed within the $6 \mathrm{~h}$ of infection contain this motif with exact match on their upstream, while only $22 \%$ ( 24 genes) of the genes expressed during the last two time points harbored it in the upstream regions. A search for putative late promoter motif in the second set of sequence resulted in a statistically insignificant highly degenerate motif $(E$-value $<3.53 \mathrm{e}+011)$ without any match to the previously reported late promoter motifs of giant viruses (Supplementary Figure 4B).

Read mapping to the $\mathrm{AaV}$ genome revealed that the expression of different genes had a large spatiotemporal variation (Figure 2A). Only three of the annotated genes from the $\mathrm{AaV}$ genome (AaV_004 and AaV_115 - hypothetical proteins and AaV_336 - a putative leucyl tRNA) were not detected as transcripts. The two terminal DUF285 domain-rich regions showed lower variation in expression values compared to other viral genes (Figure 2A). While relative expression of most of the viral genes varied across several orders of magnitude during the time course, expression of DUF285 regions stayed consistent within one order of magnitude. As a striking contrast, expression of major capsid protein was found to be dramatically high at $21 \mathrm{~h}$ - encompassing $>50 \%$ of the virus-specific reads and $\sim 6 \%$ of the entire libraries at that time point.

Out of 384 genes in AaV (Moniruzzaman et al., 2014), only 137 have nucleocytoplasmic large DNA virus orthologous groups (NCVOG) (Yutin et al., 2009) and/or cluster of orthologous groups (COG) (Tatusov et al., 2000) assignments, giving insights into their potential function (Supplementary Table 2). Based on the cluster analysis, we found seven of nine annotated viral-methyltransferases were expressed within $6 \mathrm{~h}$ of infection. Expression of three out of four genes with NCVOG category "virion structure and morphogenesis" (AaV_165, 247 and 290) was detected at 12 or $21 \mathrm{~h}$ of infection - consistent with previous observations that genes involved in the production of virus structural components are expressed late during infection 


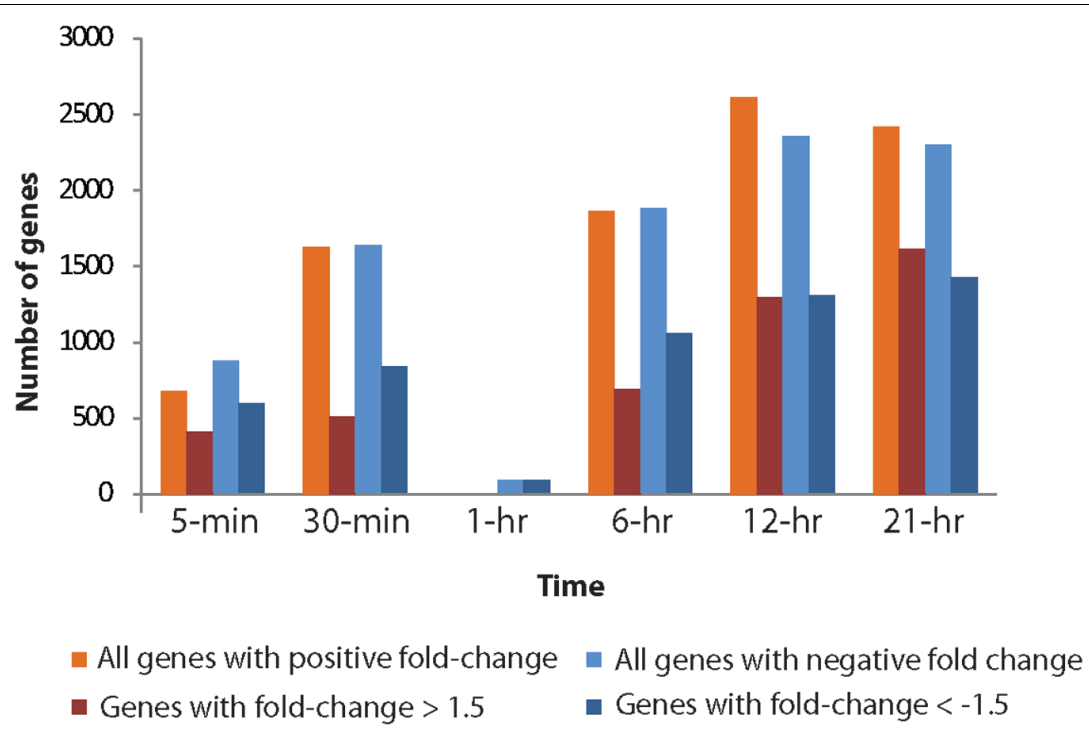

FIGURE 3 | Total number of genes up- and down-regulated in the infected host across different time points compared to the healthy cultures. Number of up- or down- regulated genes are represented on the $Y$-axis.

(Fischer et al., 2010; Legendre et al., 2010) (Supplementary Table 2). The exception was major capsid protein (AaV_096), a major structural component of the virus, which was found to be expressed immediately $(5 \mathrm{~min})$ after infection. Three ubiquitin ligases (AaV_228, 235, and 298) and two proteases (AaV_042, 066) were also found to be expressed $5 \mathrm{~min}$ post-infection, alongside a number of putative transcription factors (Supplementary Table 2). AaV has a number of genes unique among NCLDVs, which are putatively acquired by HGT from the host and other cellular organisms (Moniruzzaman et al., 2014). Among these, three carbohydrate metabolism genes (carbohydrate sulfotransferase: AaV_102, glucuronyl hydrolase: AaV_078, and pectate lyase: AaV_375) were expressed immediately after infection (Supplementary Table 2). However, the majority of HGT-acquired genes were found to be expressed only at or after $6 \mathrm{~h}$ (Supplementary Table 2). Most other genes with COG or NCVOG classifications did not show any "functionspecific” temporal pattern (Supplementary Table 2).

\section{Global Transcriptional Remodeling of the Virus-Infected Host}

Viral infection induced a dramatic and rapid reprogramming of host cell gene expression, which was reflected in the number of Aureococcus genes that were differentially expressed compared to the uninfected culture (Figure 3). Even at 5-min post-infection, we observed $13.4 \%$ of the 11,570 genes of Aureococcus were differentially expressed, with 412 genes having fold changes of $>1.5$, and 588 genes with a fold change less than -1.5 (FDRcorrected $p<0.05$ ) (Figure 3). With exception of the 1-h time point, the number of genes over or underexpressed compared to control showed a tendency to increase over time, with the highest number of genes observed to be differentially expressed occurring at the $12 \mathrm{~h}$ time point $(42.9 \%)$.
The number of differentially expressed host genes was dramatically reduced at 1-h compared to other time points: only 82 genes were found to be differentially expressed (Figure 3). All of these differentially expressed genes showed negative fold changes. Since the general trend of increasing number of differentially expressed genes over time did not apply to the 1 -h time point, it presented an "anomaly" that invited further investigation. There were $\sim 9800$ virus reads on average in the three virus-treated biological replicates from time point $1-\mathrm{h}$ (Supplementary Figure 3), which is higher than the number of virus reads in 30-min samples and lower than that of 6-h samples. Thus, the number of total viral reads during 1-h time point fit the trend of increasing viral reads over time in the treated samples. An nMDS analysis coupled with a hierarchical clustering using Bray-Curtis similarity showed that control and infected samples from 1-h time point clustered together and showed $>97.5 \%$ similarity between the replicates (Supplementary Figure 5). In contrast, corresponding control and treatment samples from other time points generally had a similarity below 95\% and clustered according to treatments.

A large number of GO categories and KEGG pathways were differentially represented across time points, except for at 1h (Figure 4 and Supplementary Figure 6). Remarkably, several processes were up- or down-regulated almost immediately after infection. For example, overrepresentation of GO term "cofactor biosynthesis" and "regulation of gene expression" was found by 5 -min post-infection, while actin and microtubule cytoskeleton, copper exporting ATPase, and racemase and epimerase activityrelated GO processes were suppressed in the infected cells. Cytoskeleton-related GO terms were suppressed throughout the infection cycle. We found increased representation of ribosome, translation, and endoplasmic reticulum-related processes in the infected culture. Mitochondria and cellular respirationrelated GO terms were also overrepresented. Notable processes 


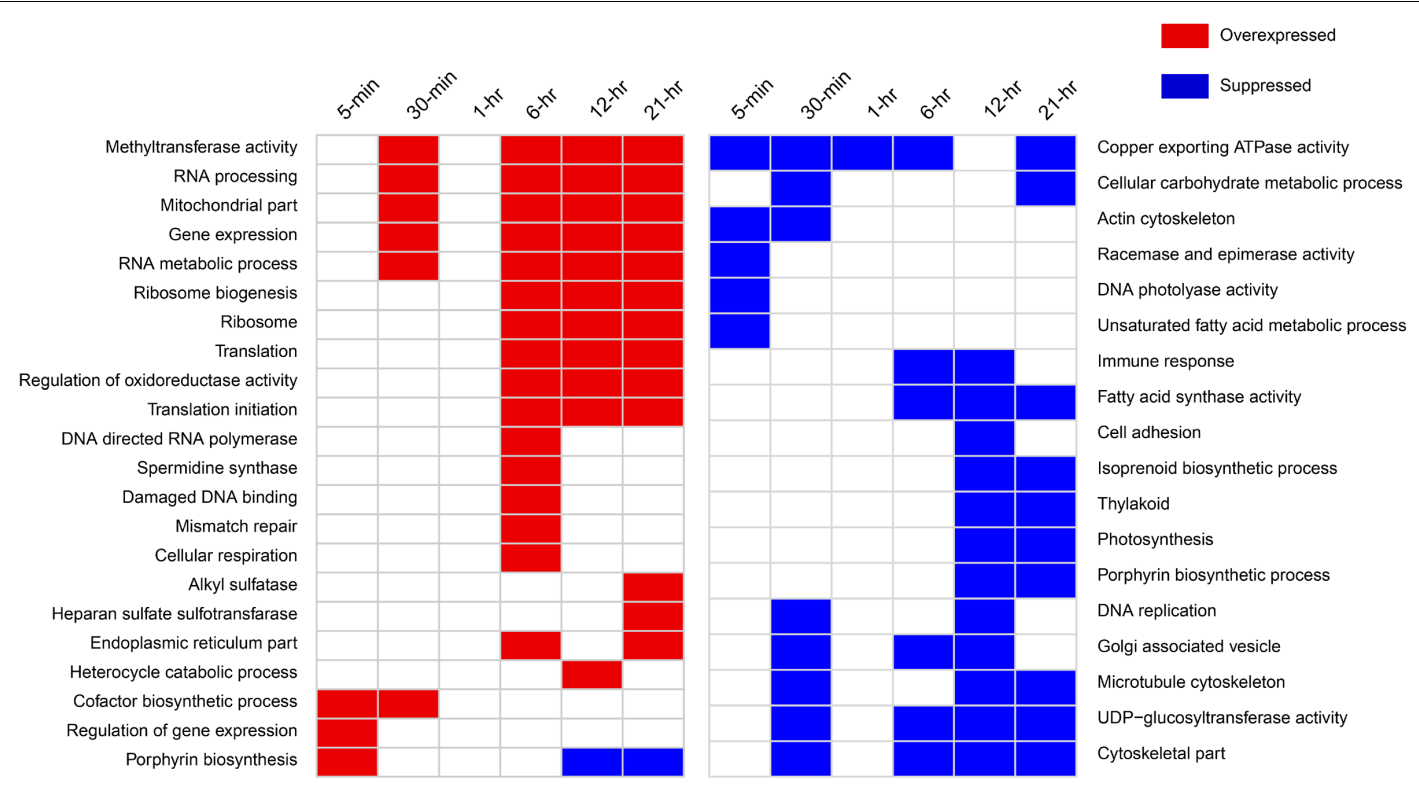

FIGURE 4 | Notable GO categories overexpressed or suppressed in the host in virus-treated samples relative to controls over different time points. Overexpressed GO categories are those significantly enriched (FDR-corrected $p<0.1$ ) in gene sets with $>1.5$-fold change, whereas suppressed GO categories are enriched in the gene sets with less than -1.5 -fold change.

that were suppressed in the infected culture were racemase and epimerase activity, unsaturated fatty acid metabolism, and Golgi-associated vesicle processes. The down-regulation of racemase and epimerase activity suggests a decrease in carbohydrate metabolism in the cell upon infection. Even though only a few genes were differentially expressed at 1-h, pathway analyses suggested increase in ribosome, butanoate, and sulfur metabolism-related gene expression at this time point (Supplementary Figure 6).

\section{DNA Mismatch Repair, "Immune Response," and Polyamine Biosynthesis}

Surprisingly, we detected a GO term "immune response" that was suppressed around 6- and 12-h post-infection (Supplementary Dataset 1). Upon closer inspection, the genes annotated by this function were found to be guanylate-binding proteins (GBPs). GBPs belong to interferon-gamma inducible GTPase superfamily that are widely known to promote defense against viruses and other intracellular pathogens in humans, mice, and other mammals (Vestal and Jeyaratnam, 2011). We determined that a number of GBP genes were down-regulated 30-min postinfection and onward (Supplementary Table 3). In addition, the phagosome pathway-related genes were also down-regulated immediately after infection, while genes involved in autophagy were down-regulated 6-h post-infection (Figure 4).

DNA mismatch repair (MMR) and damaged DNA-bindingrelated GO processes were found to be up-regulated around 6-h post-infection at transcriptional level (Figure 4). All of the genes annotated with these GO processes were found to encode proteins having MutS and MutL domains. Viral infection induced significant over-expression of a number of these genes within 5-min of infection (Supplementary Figure 7). These include a MutS homolog and a small MutS-related protein (smr). By $30 \mathrm{~min}$, more of these genes showed significantly increased expression, which include a MutS2, MutL, and another smr homolog (Supplementary Figure 7). Around 6-h, all these genes remained highly expressed compared to control. Several genes were found to be down-regulated at $12 \mathrm{~h}$ but up-regulated at $21 \mathrm{~h}$, indicating varying degree of regulatory controls acting upon them over the course of infection (Supplementary Figure 7).

Data exploration using GO analysis also revealed higher expression of spermidine synthase activity at $6 \mathrm{~h}$ postinfection compared to the control. Ornithine decarboxylase converts L-ornithine to putrescine, which is further converted to spermidine by spermidine synthase. Aureococcus homologs of ornithine decarboxylase and spermidine synthase were found to be up-regulated in the virus-infected culture from $6 \mathrm{~h}$ onward (Supplementary Figure 8). Additionally, a homolog of $N$-carbamoylputrescine amidase (Aurandraft_59241) was also found to be up-regulated during this time.

\section{Alteration of Photosynthesis and Photoprotection-Related Processes Upon Virus Infection}

We observed significant down-regulation (FDR, $p<0.1$ ) in 17 of the 62 light harvesting complex (LHC) genes in Aureococcus as early as $5 \mathrm{~min}$ after infection, indicating that the light harvesting capacity of the infected cells decreased compared to the healthy culture immediately upon infection (Supplementary Figure 8). The number of LHC genes showing negative foldchange compared to control increased through the infection time course - 41 genes at $30 \mathrm{~min}$ and 40 genes at $6 \mathrm{~h}$ had significantly 
reduced expression. By 12 and $21 \mathrm{~h}$, most of the 62 LHC genes showed significant down-regulation, with the exception of 6 genes at $12 \mathrm{~h}$ and 2 genes at $21 \mathrm{~h}$ that showed overexpression (Supplementary Figure 9). Chloroplast genes encoding proteins for Photosystem I and II during the infection ( $p s a A$, psaB, $p s a L, p s b A, p s b C$, and $p s b D$ ) were down-regulated by $5 \mathrm{~min}$ post-infection (Supplementary Table 4). Taken together, the data indicate that transcription of genes crucial for photosynthesis decreased in the virus-infected cells throughout the light cycle. During the 12- and 21-h, photosynthesis and thylakoid-related GO processes were suppressed in the infected cells compared to the non-infected ones (Figure 4). This could indicate that photosynthesis-related genes peaked in expression during midnight and pre-dawn in the healthy cultures, a phenomenon that has been observed in other algae such as Ostreococcus tauri (Monnier et al., 2010). In addition, isoprenoid biosynthesis genes were down-regulated around the same time. Expression of 3 of the 14 genes annotated with GO term "isoprenoid biosynthesis" was suppressed significantly at 5-min post-infection, while one was overexpressed (Supplementary Table 4). No significant change was detected for other isoprenoid biosynthesis genes by $5 \mathrm{~min}$. The number of transcripts with reduced expression increased over time - eight genes were down-regulated by 30 -min and 6-h of infection (Supplementary Table 5). This data indicated a decrease in isoprenoid biosynthesis-related transcripts in the virus-treated culture throughout the infection process.

The heme biosynthesis pathway, which leads to the production of photosynthetic pigments including chlorophyll a and other tetrapyrrolic pigments, is a crucial metabolic pathway in photosynthetic organisms (Obornik and Green, 2005). While genes involved in light harvesting, photosystem structure, and isoprenoid biosynthesis were generally under-expressed, we found porphyrin biosynthesis genes in this pathway to be overexpressed immediately after infection (Figure 5). All the genes involved in synthesis of the precursor of protoporphyrin-X were up-regulated immediately after infection, but were downregulated by 30 -min post-infection (Figure 5). In contrast, genes involved in chlorophyll $a$ biosynthesis from protoporphyrin$\mathrm{X}$ did not show significant up- or down-regulation at this time (Figure 5). Collectively, this data indicate that porphyrin derivatives accumulated early in the infected cell, possibly leading to photooxidative damage of different cellular components, including chloroplasts (Reinbothe et al., 1996). Additionally, genes involved in DNA photolyase activity was found to be downregulated 5-min post-infection (Figure 4) - a process critical in repairing UV-mediated formation of pyrimidine dimers in DNA (Thiagarajan et al., 2011).

\section{Changes in Expression Associated With the Selenoproteome}

Aureococcus has 59 predicted selenoproteins - the highest reported among all eukaryotes (Gobler et al., 2011). Out of these, 35 showed significant (FDR, $p<0.1$ ) deregulation at least at one time point (Figure 6). While several selenoproteins genes were found to be under-expressed immediately postinfection, at 12 - and $21-\mathrm{h}$ a large number of selenoproteins genes showed increased expression relative to controls (Figure 6). We found $O$-phosphoseryl-tRNA ( $\mathrm{Sec}$ ) selenium transferase, a gene involved in producing selenocysteinyl-tRNA from L-seryltRNA (Sec) to be overexpressed (Supplementary Figure 10). Cystathionine beta-lyase and Selenocysteine (Sec) lyase, two genes involved in conversion of $\mathrm{Sec}$ into methionine and alanine, also showed increased expression compared to control (Supplementary Figure 10). Although no known selenium transporter has been characterized in Aureococcus, it is known that opportunistic transport of selenium using phosphate transporters might be common in plants, fungi, and algae (Lazard et al., 2010). Aureococcus has six annotated phosphate transporters. Among these, either three or four of the transporters showed significantly higher expression at 12and 21-h, respectively, during infection compared to control culture (Supplementary Figure 11). Five of the overexpressed selenoprotein genes were methionine sulfoxide reductases (MSR) (Figure 6), genes involved in reversing the oxidation of methionine by reactive oxygen species (ROS), thereby repairing the oxidative damage in proteins (Moskovitz, 2005). Three copies of glutathione peroxidases (GPx) were also over-expressed compared to control, which are crucial in reducing $\mathrm{H}_{2} \mathrm{O}_{2}$ or organic hydroperoxides, thereby minimizing oxidative damage to cellular components (Ursini et al., 1995). Glutathione-Stransferase (GST), a selenoprotein gene with diverse function in cellular stress protection, was over-expressed during the last three time points. GSTs have diverse functions in the cell, including detoxification of electrophilic metabolites of xenobiotics into less reactive compounds by catalyzing their conjugation with glutathione (GSH) (Veal et al., 2002). GSTs are also known to participate in oxidative stress protection by conjugating GSH with secondary ROS molecules that are produced upon ROS reacting with cellular constituents (Danielson et al., 1987). In addition, some GSTs show GPx activity (Tan and Board, 1996). Sel $\mathrm{U}$ and Sel H, two selenoproteins involved in redox functions and Sep15, a transcript whose product is involved in protein folding in endoplasmic reticulum (Labunskyy et al., 2009) were overexpressed in the late stage of virus infection (Figure 6).

A number of genes encoding redox active proteins not incorporating selenium were also overexpressed during the last two time points. This includes a $\mathrm{Cu}-\mathrm{Zn}$ superoxide dismutase (Aurandraft_59136), which dismutates superoxide anion $\left(\mathrm{O}_{2}^{-}\right)$, leading to production of $\mathrm{H}_{2} \mathrm{O}_{2}$. We detected overexpression of a dehydroascorbate reductase homolog (Aurandraft_67072), which is involved in recycling of ascorbate, during the last three time points. Ascorbate acts as a key antioxidant in the cell by directly neutralizing superoxide radicals, singlet oxygen, or hydroxyl radical (Noctor and Foyer, 1998).

\section{DISCUSSION}

\section{Transcriptional Landscape of AaV Infection}

This study provides initial insight into the gene expression dynamics of an algal virus in the Mimiviridae clade (Santini et al., 2013). AaV has a 21-30 h infection cycle, with free 

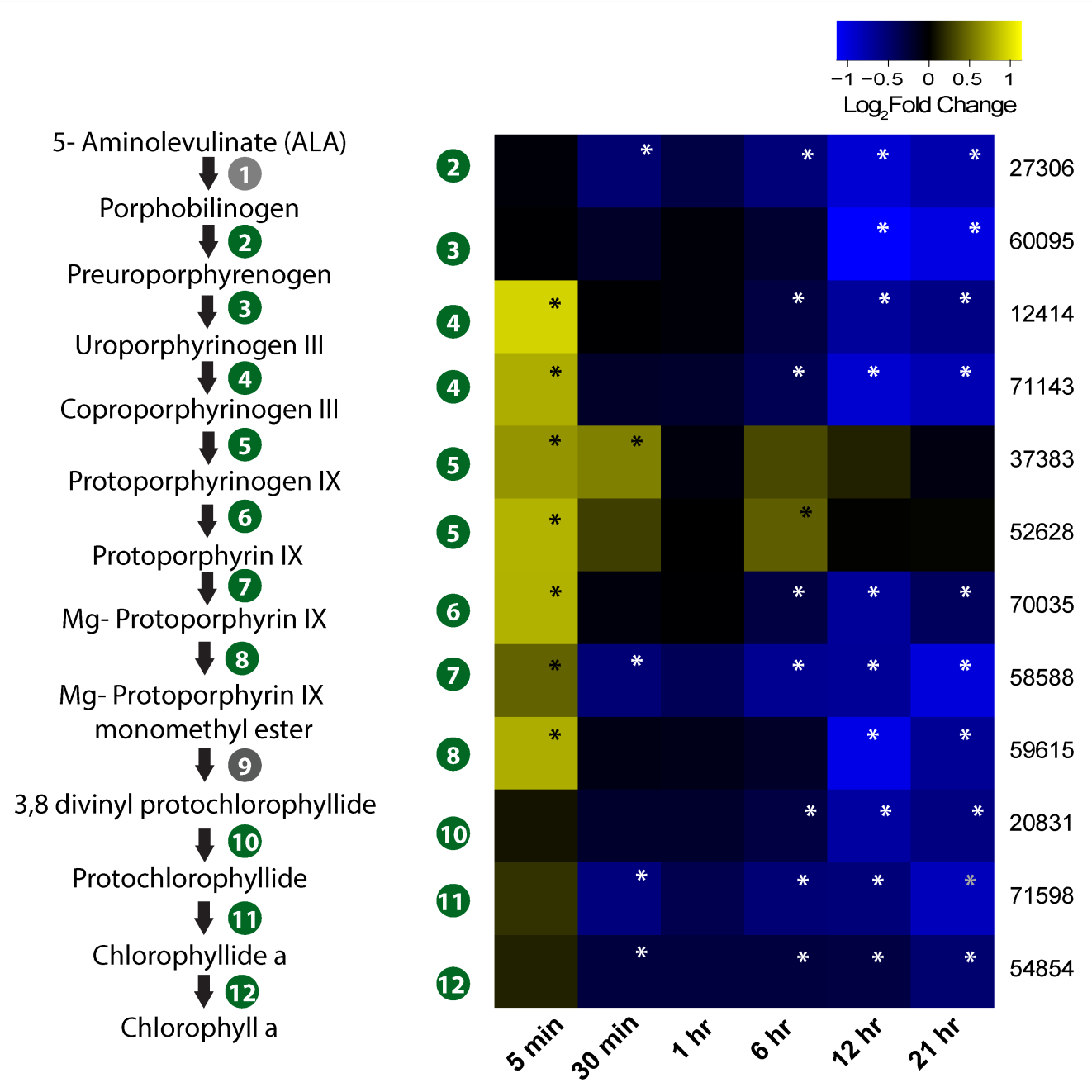

FIGURE 5 | Expression profile of genes involved in porphyrin and chlorophyll biosynthesis in the infected culture. The pathway from ALA to chlorophyll a biosynthesis is also presented. Genes marked in gray circle (1 and 9) are not annotated in Aureococcus. Numbers given on the right side of the heatmap are JGl IDs. Annotated genes are as follows: 27306 - hydroxymethylbilane synthase/porphobilinogen deaminase; 60095 - uroporphyrinogen synthase; 12414 and 71143 uroporphyrinogen decarboxylase; 37383 and 52628 - coproporphyrinogen III oxidase; 70035 - protoporphyrinogen oxidase chlorophyll precursor; 58588 - Mg chelatase ATPase; 59615 - mg protoporphyrin IX methyltransferase; 20831 - 3,8-divinyl protochlorophyllide a 8-vinyl reductase; 71598 - protochlorophyllide reductase; 54854 - chlorophyll synthase. Significant fold changes (FDR, $p \leq 0.1$ ) are marked with asterisks.

virus production observable by $21 \mathrm{~h}$ post-infection, which steadily increases over time (Brown and Bidle, 2014). The almost immediate transcription of viral genes indicated a rapid modulation of host cellular processes directed toward transcribing the viral mRNAs (Figure 2A and Supplementary Figure 3). Fast transcription of viral genes was also observed in the Chlorella-infecting virus PBCV-1 transcriptome, where viral transcripts were detected 7 min post-infection (Blanc et al., 2014). How giant viruses accomplish this rapid transcription upon infection is an open question. It has been established that giant viruses like Mimivirus and Cafeteria roenbergensis virus incorporate numerous protein products within their capsids (Renesto et al., 2006; Fischer et al., 2014). Interestingly, Mimivirus particles package 12 transcription-related protein products, including all five DNA polymerase subunits and four transcription factors encoded by the viral genome
(Renesto et al., 2006). This suggests that the fast transcription of Mimivirus genes could happen immediately after host cell entry. In addition, a qPCR approach could detect several Mimivirus transcripts from purified virus particles (Raoult et al., 2004), although DNA and RNA contamination of the particles cannot be completely ruled out. Also, RNA-seq analysis identified viral transcripts within $15 \mathrm{~min}$ of virus addition to Acanthamoeba culture (Legendre et al., 2010). However, this cannot definitively answer whether those transcripts were packaged in the particles or were transcribed immediately upon viral entry. It is possible that the appearance of viral transcript within $5 \mathrm{~min}$ of $\mathrm{AaV}$ infection resulted from the presence of mRNA and/or transcription associated enzymes within the virus particles. It has also been demonstrated that for Mimivirus (Legendre et al., 2010), C. roenbergensis virus (Fischer et al., 2010) and PBCV-1 (Blanc et al., 2014) almost all the genes are detected during the 


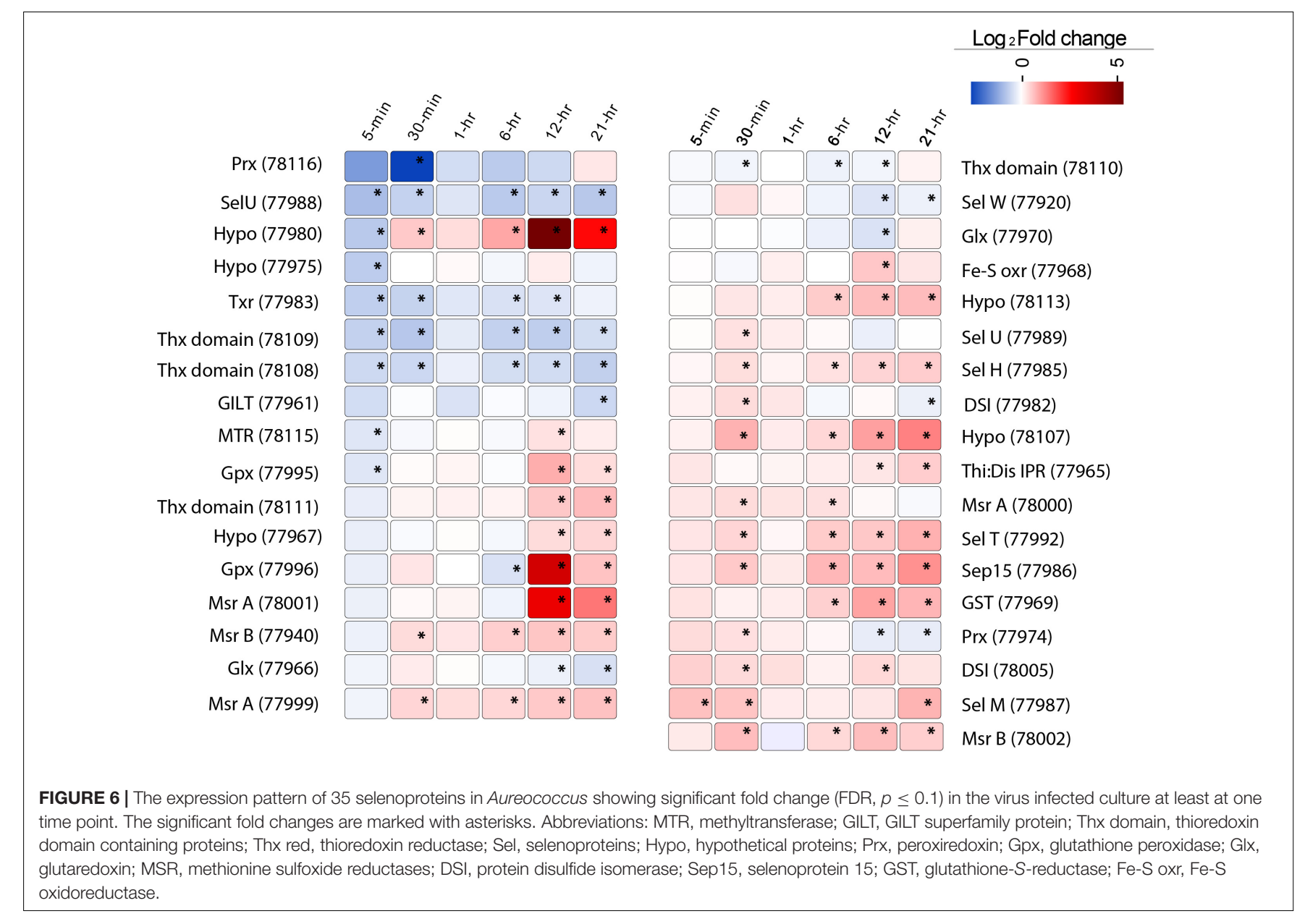

course of infection: $\mathrm{AaV}$ is not an exception. An interesting observation was the low level yet relatively stable expression of the terminal DUF285 domain containing genes compared to other viral genes, majority of which had increased expression level as time progressed. Terminally repetitive genes like these are a common feature of Mimiviridae members and are thought to be originated from massive gene duplication (Raoult et al., 2004; Fischer et al., 2010; Moniruzzaman et al., 2014). The regulatory mechanism behind the low expression dynamics of these genes is unknown - however, the role of methylation or binding of specific factors suppressing the expression of these genes can't be ruled out. A highly conserved motif was found to be present upstream of these DUF285 genes (Moniruzzaman et al., 2014), which might be a candidate-binding site for certain regulatory factor(s).

Viral transcription increased over time, and at $21 \mathrm{~h}$ postinfection (just before the cell lysis) $\sim 15 \%$ of the reads came from viral transcripts. This is a low proportion of viral reads compared to what has been observed in Mimivirus (Legendre et al., 2010) and PBCV-1 (Blanc et al., 2014) infection transcriptomes. It appears that not all the Aureococcus cells may be infected during the first cycle, since it took the equivalent of two consecutive infection cycles ( $48 \mathrm{~h}$ ) for a $\sim 98 \%$ reduction from the initial cell count. A study on EhV transcriptomics and metabolomics revealed that E. huxleyi cell counts remained relatively unchanged by $24 \mathrm{~h}$ of infection (Rosenwasser et al., 2014), similar to Aureococcus counts in this study. However, in that study $\sim 75-80 \%$ of the reads originated from EhV transcripts by $24 \mathrm{~h}$. Why we saw only $15 \% \mathrm{AaV}$ reads around the time of lytic burst remains an open question. This phenomenon might be a result of the quantitative dynamics of $\mathrm{AaV}$ transcription or this virus exploiting more host machinery than the other "giants." It is also possible that overwhelming majority of the reads originated from both infected and uninfected cells during the first lytic cycle and we see proportionally less viral reads within the sequence space. In the future a better understanding of virus-host interactions, the infectivity of $\mathrm{AaV}$ particles, and the availability of infection transcriptomes from other giant viruses will help resolve this question.

The enrichment of the octamer motif "AAAAATGA" in the genes expressed within $6 \mathrm{~h}$ of infection suggests that this is the early promoter motif of AaV (Supplementary Figure 4A). This motif is similar to the reported Mimivirus and C. roenbergensis virus early promoter motif “AAAATTGA" (Fischer et al., 2010; Legendre et al., 2010), with only one mismatch (at the fifth position). In contrast, $\mathrm{AaV}$ early promoter motif was not similar to that of algal virus PBCV-1, which is a member of Phycodnaviridae. This may indicate a degree of evolutionary 
conservation of the early promoter motif across the Mimiviridae clade. Analyzing the genome sequences of other Mimiviridae members might provide further support to this observation.

Giant viruses contain a diverse array of genes and even functional proteins (e.g., Fischer et al., 2014) within their capsids, which they use to transform their host's cellular environment. In case of AaV, the immediately expressed genes included both proteases and ubiquitin ligases, which possibly participate in degrading the host proteins. Several transcription factors and RNA polymerase subunits were also expressed at the same time, which likely allowed transcription of the virus genes independent of at least some of the host's apparatus (Supplementary Table 2). The expression of carbohydrate metabolism genes (putatively acquired by HGT) in $\mathrm{AaV}$ also leads to some intriguing possibilities. It is known that unsaturated glucuronyl hydrolases remove the terminal unsaturated sugar from the oligosaccharide products released by polysaccharide lyases (Jongkees and Withers, 2011). Healthy Aureococcus cells are surrounded by a fibrous glycocalyx, which is absent from the virus-infected cells (Gastrich et al., 1998): it is thus compelling to speculate that the role of a polysaccharide lyase and glucuronyl hydrolase during infection is to make the cell membrane accessible for virus attachment. Analysis of the proteome of $\mathrm{AaV}$ particles will be necessary to determine whether these proteins are packaged within the capsid which could be used to target the host membrane.

\section{The Aureococcus "Virocell" - Transcriptional Remodeling Upon Virus Infection}

One observation within this study was a rapid transcriptional response of the host after virus treatment (Figure 3). In part the differentially expressed gene pool might reflect host defense response to virus attack. However, this response also potentially includes genes that are rapidly manipulated by the virus to transform the cellular environment in favor of virus propagation. This rapid change at transcription level perhaps represents how the transformation of a healthy cell into a "virocell" (Forterre, 2011) is initiated. An interesting observation was the dramatic reduction in number of deregulated genes at $1-\mathrm{h}$ time point. Our analyses indicate that this phenomenon is not a result of human error or sample mislabeling. This likely has a biological basis, since control and infected RNA-seq data at 1-h show higher similarity in nMDS space compared to other control and infection sample pairs (Supplementary Figure 5). Underlying cause of this observation is yet to be determined. We observed deregulation of numerous genes and cellular processes across all time points but 1 -h, which provide important insights into the mechanistic basis of $\mathrm{AaV}$ propagation. Higher expression of ribosome, translation, and endoplasmic reticulum-related processes possibly resulted in elevation of protein synthesis, whereas suppression of Golgi vesicle-associated processes indicate that $\mathrm{AaV}$ infection affected sorting of cellular proteins to their respective destinations (Rodriguez-Boulan and Müsch, 2005). Increased energy requirement for viral replication was indicated by overrepresentation of mitochondria and cellular respiration-related GO terms (Sanchez and Lagunoff, 2015). All the Aureococcus genes annotated within the GO category "unsaturated fatty acid metabolic processes" are delta fatty acid desaturases - enzymes incorporating desaturation (carbon/carbon double bond) in fatty acids. These enzymes have important role in maintaining membrane fluidity during stress (Aguilar and de Mendoza, 2006). Some cyanophages encode for fatty acid desaturases (Roitman et al., 2017), and it has been suggested that maintenance of membrane fluidity is critical for assembly and activity of membrane proteins like D1 protein in photosystem II (Gombos et al., 1997). One of the possible effect of deregulation of these genes upon $\mathrm{AaV}$ infection could be compromised structure and function of the photosynthetic apparatus in the infected Aureococcus cells. The deregulation of the GBPs and phagosome pathway in virus infected cells is interesting since GBPs are known to transport antimicrobial peptides, NADPH oxidase components, and the machinery of autophagy in the phagosomal compartments (Dupont and Hunter, 2012). These observations indicate that GBPs might be part of a defense network in Aureococcus against infection. Circumvention of this network is probably crucial in establishing successful infection by AaV.

The possible roles of polyamines in propagation of several viruses (Raina et al., 1981; Baumann et al., 2007) have been previously noted - including their role in neutralizing the negatively charged nucleic acid inside the capsid (Gibson and Roizman, 1971). Interestingly, Chlorella virus PBCV-1, NY2A, and MT325 encode a complete polyamine biosynthetic pathway in their genomes, enabling them to synthesize homospermidine and putrescine (Baumann et al., 2007). While no polyamine biosynthesis genes could be located on $\mathrm{AaV}$ genome, increased polyamine biosynthesis in infected Aureococcus cells (Supplementary Figure 8) alongside adoption of polyamine synthesis genes by Chlorella viruses might indicate a widespread role of polyamines in giant virus life cycles.

Relative to competing plankton, Aureococcus has a larger number of nuclear-encoded LHC proteins, which augment the photosynthetic reaction center in collecting light energy (Gobler et al., 2011). It is known that lower light level can delay the virus-mediated lysis of Aureococcus, and photosynthetic efficiency is not significantly different between infected and non-infected cultures within 24-h of infection (Gobler et al., 2007). However, the molecular basis of how AaV infection can influence the host photosynthetic capacity is largely unknown. Immediately after infection, transcripts for photosynthesis-related processes proportionally decreased relative to control, with increasing number of LHC proteinencoding genes being down-regulated as infection progressed (Supplementary Figure 9). Along with the LHC genes, isoprenoid biosynthesis genes were also downregulated. Isoprenoids are an important functional and structural part of the photosynthetic apparatus and photosynthetic electron carriers, with roles in regulating the fluidity of photosynthetic membranes. (Havaux, 1998). Also, isoprenoid compounds like zeaxanthin and $\beta$-carotene are involved in photoprotection - they dissipate excessive light energy through heat (Peñuelas and MunnéBosch, 2005). A possible consequence of the suppression of 
isoprenoid biosynthesis genes could be structural damage of the photosynthetic components of the infected cells. $\mathrm{AaV}$ propagation was found to be adversely affected at low light with cultures incubated in low light $\left(\sim 3 \mu \mathrm{mol}\right.$ quanta $\left.\mathrm{m}^{-2} \mathrm{~s}^{-1}\right)$ taking more than 7 days to be reduced to $<10^{4}$ cells $/ \mathrm{ml}$ compared to high light $\left(\sim 110 \mu \mathrm{mol}\right.$ quanta $\left.\mathrm{m}^{-2} \mathrm{~s}^{-1}\right)$ incubated culture, which took 3 days to be reduced to similar concentration (Gobler et al., 2007). Down-regulation of photosynthesis was also observed in Chlorella upon infection with PBCV-1 (Seaton et al., 1995) and Heterosigma akashiwo infected by either RNA or DNA viruses (Philippe et al., 2003). Photosynthesis was found to be down-regulated in a wide range of plants in response to pathogen invasion (e.g., virus and bacteria) (Bilgin et al., 2010) and was suggested to be an adaptive response to biotic attack. It is important to note that down-regulation of gene expression doesn't necessarily mean immediate loss of function specifically, the proteins involved in light reaction might have a long functional lifetime (Bilgin et al., 2010). Thus, the actual effect of immediate down-regulation of photosynthesis gene expression on viral attack remains to be elucidated. It was proposed that slow turnover of many photosynthesis-related proteins allows the host to redirect resources for immediate defense mechanisms without dramatically reducing its photosynthetic capacity (Bilgin et al., 2010). High light requirement of the virus and the capacity of Aureococcus to grow in a low light environment might itself act as a natural defense mechanism at the community level, where delayed virus production can eventually lead to fewer host-virus contacts and infection.

In photosynthetic organisms, different chlorophyll precursors are formed as part of its biosynthetic pathway. However, accumulation of such precursors, especially protoporphyrin IX, can lead to photosensitivity (Inagaki et al., 2015). In the presence of light, the chlorophyll precursors with a porphyrin structure interact with triplet oxygen molecule to produce highly reactive singlet oxygen, which in turn can catalyze peroxidation of lipids and other cellular macromolecules (Rüdiger, 2009). It has also been demonstrated that various porphyrin derivatives might have broad antiviral activity - however, the activity is mostly extracellular. For example, an alkylated porphyrin (chlorophyllide) was found to cause damage to the hepatitis B-virus capsid (Guo et al., 2011), leading to loss of virion DNA. Thus, increase in porphyrin synthesis-related gene expression might lead to increased porphyrin concentrations in $\mathrm{AaV}$ infected cells, elevating the oxidative stress and making the cellular environment hostile for the invading viral DNA (Mock et al., 1998). Porphyrin compounds might also damage the components of the infected cells that are important for completion of $\mathrm{AaV}$ replication cycle. Intriguingly, $\mathrm{AaV}$ encodes a pheophorbide $\mathrm{A}$ oxygenase gene $\left(\mathrm{AaV}_{2}\right.$ 372) which is a key regulator in heme/chlorophyll breakdown (Hörtensteiner, 2013). Transcripts for this gene were initially detected at 6-h postinfection (Supplementary Table 1). Presence of this transcript poses the interesting possibility that $\mathrm{AaV}$ might use it to counteract the oxidative damage induced by high porphyrin biosynthesis. Together, up-regulation of porphyrin biosynthesis genes and concomitant down-regulation of DNA photolyase (Figure 4) might work as one of the first lines of host defense - an oxidative intracellular environment with a suppression of DNA repair activity. Recently, photolyase was reported to be part of the CroV proteome (Fischer et al., 2014). It was also found that majority of the packaged proteins, including photolyase, were late proteins (Fischer et al., 2014). A photolyase is also encoded into $\mathrm{AaV}$ genome, which was found to be expressed late $(12 \mathrm{~h}$ post-infection). It is possible that proteins involved in subversion of host defense are also packaged in the $\mathrm{AaV}$ virion. AaV also encodes MutS (Moniruzzaman et al., 2014), a protein putatively involved in DNA MMR (Wilson et al., 2014). Diverse viruses are known to exploit the cellular DNA damage repair machineries (e.g., Weinbauer et al., 1997). In herpes simplex virus-1 (HSV-1), cellular MMR proteins are crucial for efficient replication which is evidenced by accumulation of these proteins in the replication centers (Ogata et al., 2011). The role of host MMR system in giant virus replication is unknown; however, MutS homologs are present in all the known members of the Mimiviridae family (Ogata et al., 2011; Wilson et al., 2014). The modulation of host MMR gene expression by AaV (Supplementary Figure 7) indicates that both virus- and host-encoded MMR machineries are important for successful propagation of $\mathrm{AaV}$ and likely other Mimiviridae members.

The majority of the selenoproteins characterized to date have redox-active functions; however, they can also have a wide range of biological roles (Labunskyy et al., 2014). Some viruses can encode Sec-containing proteins, with bioinformatics evidence provided for several mammalian viruses (Taylor et al., 1997): indeed, a Sec-containing GPx experimentally characterized in HIV-1 (Zhao et al., 2000). Given the unrivaled compendium of Aureococcus selenoprotein encoding genes within the eukaryotic domain, we were interested in how the expressions of these genes would be modulated by AaV infection and their possible role in virus propagation. Our study indicates that a number of up-regulated selenoprotein genes are possibly involved in viral protein synthesis and preventing oxidation of these viral proteins, especially during the late phase of infection (Figure 6). It has been demonstrated that Sec-containing MSR are efficient, showing 10-50-fold higher enzymatic activity compared to the Cyscontaining MSRs (Kim et al., 2006). Additionally, selenoproteins deemed crucial in regulating the redox state of the cells (e.g., GPx and dehydroascorbate reductase) were also overexpressed during infection. The cellular pro-/antioxidant balance is a highly complex process, involving a cascade of enzymatic activity and interconnected pathways. As was aptly put by Schwarz (1996), "it is difficult to distinguish between association and causation as well as between primary and secondary effects of a given virus on ROS mediated cellular injury." In EhV, observations from transcriptome data coupled to targeted experiments revealed an elevated production of GSH along with $\mathrm{H}_{2} \mathrm{O}_{2}$ accumulation in the infected cells. Interestingly, addition of a peroxidase inhibitor (esculetin) or a $\mathrm{H}_{2} \mathrm{O}_{2}$ inhibitor (potassium iodide) to the infected cells dramatically reduced cell death and virus production, indicating a complex yet important role of virus-mediated ROS and antioxidant modulation of host cells for successful virus production (Sheyn et al., 2016). While in AaV-infected cultures we observed up-regulation of a superoxide dismutase gene, suggesting accumulation of $\mathrm{H}_{2} \mathrm{O}_{2}$ (no catalase is annotated in 
Aureococcus genome), no further inference can be made on its role without targeted experiments. However, up-regulation of a large number of selenoprotein genes involved in protein damage repair, folding, and other redox functions can indeed be interpreted as a response to increase in cellular oxidative stress under which viral protein synthesis and assembly were likely progressing. Additionally, increase in Sec biosynthesis and its conversion to other amino acids (Supplementary Figure 10) point to the possibility of increased requirement of selenium for the infected cells. Although we observed overexpression of phosphate uptake genes in the infected cells, it is not possible to link this with increased selenium uptake without further experiments. Indeed, this could simply imply that $\mathrm{AaV}$ proliferation may require elevated concentration of phosphate in cell. Phosphate depletion has been shown to massively reduce the burst size of $\mathrm{PpV}$ in Phaeocystis pouchetii (Carreira et al., 2013), PBCV in Chlorella sp. (Carreira et al., 2013), and MpV in Micromonas pusilla (Maat et al., 2014). Further studies will be necessary to elucidate the effect of selenium deficiency and mechanism of selenium uptake during the replication of $\mathrm{AaV}$ and other algal viruses.

\section{CONCLUSION}

Host-virus interactions at nanoscale eventually shape ecosystem processes at geographical scales (Brussaard et al., 2008). Resolving the molecular aspects of ecologically relevant hostvirus interactions is critical to understand the role of viruses in the biogeochemical processes, as well as the factors that drive the co-evolution of virus-host systems (Rosenwasser et al., 2016). In this study, we gained insights into the transcriptomic response of a harmful alga upon infection by a giant virus. The ultimate fate of a cell going through lytic infection is to produce progeny viruses, which is accomplished through a different transcriptomic and metabolic trajectory relative to a healthy cell. The most likely outcome of this massive transcriptional response is that a reprogrammed metabolic profile-specific metabolites might

\section{REFERENCES}

Aguilar, P. S., and de Mendoza, D. (2006). Control of fatty acid desaturation: a mechanism conserved from bacteria to humans. Mol. Microbiol. 62, 1507-1514. doi: 10.1111/j.1365-2958.2006.05484.x

Alikhan, N.-F., Petty, N., Ben Zakour, N., and Beatson, S. (2011). BLAST ring image generator (BRIG): simple prokaryote genome comparisons. BMC Genomics 12:402. doi: 10.1186/1471-2164-12-402

Angly, F., Rodriguez-Brito, B., Bangor, D., Mcnairnie, P., Breitbart, M., Salamon, P., et al. (2005). PHACCS, an online tool for estimating the structure and diversity of uncultured viral communities using metagenomic information. BMC Bioinformatics 6:41. doi: 10.1186/14712105-6-41

Ankrah, N. Y., May, A. L., Middleton, J. L., Jones, D. R., Hadden, M. K., Gooding, J. R., et al. (2014). Phage infection of an environmentally relevant marine bacterium alters host metabolism and lysate composition. ISME J. 8, 1089-1100. doi: 10.1038/ismej.2013.216

Bailey, T. L., Boden, M., Buske, F. A., Frith, M., Grant, C. E., Clementi, L., et al. (2009). MEME Suite: tools for motif discovery and searching. Nucleic Acids. Res. 37, W202-W208. doi: 10.1093/nar/gkp335 regulate viral replication and might be incorporated in the virion particles. The altered metabolism of virus-infected cells might even influence large-scale ecological processes; for example, differential uptake or release of specific compounds might alter the nutrient dynamics, thereby affecting the coexisting microbial communities (Ankrah et al., 2014). This study will provide an important foundation to generate and test new hypotheses regarding individual metabolic or regulatory processes that can have important biogeochemical consequences, and perhaps more importantly, place the "virocell" into a better ecological context.

\section{AUTHOR CONTRIBUTIONS}

MM and SW designed the experiments and secured funding. MM, EG, and SW carried out the experiments and analysis and wrote the paper.

\section{FUNDING}

This project was funded by a College of Arts \& Science (UTK) Penley Fellowship awarded to MM. Further support was provided by the Gordon and Betty Moore Foundation (Grant No. 4971) and a Kenneth \& Blaire Mossman Endowed Professorship to SW.

\section{ACKNOWLEDGMENTS}

The authors thank Mark McDonald for his valuable help in setting up the experiment and sample collection.

\section{SUPPLEMENTARY MATERIAL}

The Supplementary Material for this article can be found online at: https://www.frontiersin.org/articles/10.3389/fmicb. 2018.00752/full\#supplementary-material

Bailey, T. L., and Elkan, C. (1994). Fitting a mixture model by expectation maximization to discover motifs in biopolymers. Proc. Int. Conf. Intell. Syst. Mol. Biol. 2, 28-36.

Baumann, S., Sander, A., Gurnon, J. R., Yanai-Balser, G. M., Van Etten, J. L., and Piotrowski, M. (2007). Chlorella viruses contain genes encoding a complete polyamine biosynthetic pathway. Virology 360, 209-217. doi: 10.1016/j.virol. 2006.10.010

Benjamini, Y., and Hochberg, Y. (1995). Controlling the false discovery rate: a practical and powerful approach to multiple testing. J. R. Stat. Soc. B (Methodological) 57, 289-300.

Bilgin, D. D., Zavala, J. A., Zhu, J. I. N., Clough, S. J., Ort, D. R., and Delucia, E. H. (2010). Biotic stress globally downregulates photosynthesis genes. Plant Cell Environ. 33, 1597-1613. doi: 10.1111/j.1365-3040.2010.02167.x

Blanc, G., Mozar, M., Agarkova, I. V., Gurnon, J. R., Yanai-Balser, G., Rowe, J. M., et al. (2014). Deep RNA sequencing reveals hidden features and dynamics of early gene transcription in Paramecium bursaria Chlorella Virus 1. PLoS One 9:e90989. doi: 10.1371/journal.pone.0090989

Brown, C. M., and Bidle, K. D. (2014). Attenuation of virus production at high multiplicities of infection in Aureococcus anophagefferens. Virology 466-467, 71-81. doi: 10.1016/j.virol.2014.07.023 
Brussaard, C. P., Wilhelm, S. W., Thingstad, F., Weinbauer, M. G., Bratbak, G., Heldal, M., et al. (2008). Global-scale processes with a nanoscale drive: the role of marine viruses. ISME J. 2, 575-578. doi: 10.1038/ismej.2008.31

Carreira, C., Heldal, M., and Bratbak, G. (2013). Effect of increased pCO2 on phytoplankton-virus interactions. Biogeochemistry 114, 391-397. doi: 10.1007/ s10533-011-9692-x

Chang, J. H., and Tong, L. (2012). Mitochondrial poly(A) polymerase and polyadenylation. Biochim. Biophys. Acta 1819, 992-997. doi: 10.1016/j.bbagrm. 2011.10.012

Clarke, K. R. (1993). Non-parametric multivariate analyses of changes in community structure. Aust. J. Ecol. 18, 117-143. doi: 10.1111/j.1442-9993.1993. tb00438.x

Claverie, J. M., and Abergel, C. (2010). Mimivirus: the emerging paradox of quasi-autonomous viruses. Trends Genet. 26, 431-437. doi: 10.1016/j.tig.2010. 07.003

Danielson, U. H., Esterbauer, H., and Mannervik, B. (1987). Structureactivity relationships of 4-hydroxyalkenals in the conjugation catalysed by mammalian glutathione transferases. Biochem. J. 247: 707. doi: 10.1042/bj2 470707

Dupont, C. D., and Hunter, C. A. (2012). Guanylate-binding proteins: niche recruiters for antimicrobial effectors. Immunity 37, 191-193. doi: 10.1016/j. immuni.2012.08.005

Filee, J., Siguier, P., and Chandler, M. (2007). I am what I eat and I eat what I am: acquisition of bacterial genes by giant viruses. Trends Genet. 23, 10-15. doi: 10.1016/j.tig.2006.11.002

Fischer, M. G., Allen, M. J., Wilson, W. H., and Suttle, C. A. (2010). Giant virus with a remarkable complement of genes infects marine zooplankton. Proc. Natl. Acad. Sci. U.S.A. 107, 19508-19513. doi: 10.1073/pnas.1007 615107

Fischer, M. G., Kelly, I., Foster, L. J., and Suttle, C. A. (2014). The virion of Cafeteria roenbergensis Virus (CroV) contains a complex suite of proteins for transcription and DNA repair. Virology 466-467, 82-94. doi: 10.1016/j.virol. 2014.05.029

Forterre, P. (2011). Manipulation of cellular syntheses and the nature of viruses: the virocell concept. C. R. Chim. 14, 392-399. doi: 10.1016/j.crci.2010.06.007

Gastrich, M., Leigh-Bell, J., Gobler, C., Roger Anderson, O., Wilhelm, S. W., and Bryan, M. (2004). Viruses as potential regulators of regional brown tide blooms caused by the alga, Aureococcus anophagefferens. Estuaries 27, 112-119. doi: 10.1007/BF02803565

Gastrich, M. D., Anderson, O. R., Benmayor, S. S., and Cosper, E. M. (1998). Ultrastructural analysis of viral infection in the brown-tide alga, Aureococcus anophagefferens (Pelagophyceae). Phycologia 37, 300-306. doi: 10.2216/i00318884-37-4-300.1

Gibson, W., and Roizman, B. (1971). Compartmentalization of spermine and spermidine in the Herpes Simplex virion. Proc. Natl. Acad. Sci. U.S.A. 68, 2818-2821. doi: 10.1073/pnas.68.11.2818

Gobler, C. J., Anderson, O. R., Gastrich, M. D., and Wilhelm, S. W. (2007). Ecological aspects of viral infection and lysis in the harmful brown tide alga Aureococcus anophagefferens. Aquat. Microb. Ecol. 47, 25-36. doi: 10.3354/ ame 047025

Gobler, C. J., Berry, D. L., Dyhrman, S. T., Wilhelm, S. W., Salamov, A., Lobanov, A. V., et al. (2011). Niche of harmful alga Aureococcus anophagefferens revealed through ecogenomics. Proc. Natl. Acad. Sci. U.S.A. 108, 4352-4357. doi: $10.1073 /$ pnas. 1016106108

Gobler, C. J., Lonsdale, D. J., and Boyer, G. L. (2005). A review of the causes, effects, and potential management of harmful brown tide blooms caused by Aureococcus anophagefferens (Hargraves et Sieburth). Estuaries 28, 726-749. doi: 10.1007/BF02732911

Gombos, Z., Kanervo, E., Tsvetkova, N., Sakamoto, T., Aro, E. M., and Murata, N. (1997). Genetic enhancement of the ability to tolerate photoinhibition by introduction of unsaturated bonds into membrane glycerolipids. Plant Physiol. 115, 551-559. doi: 10.1104/pp.115.2.551

Guo, H., Pan, X., Mao, R., Zhang, X., Wang, L., Lu, X., et al. (2011). Alkylated porphyrins have broad antiviral activity against Hepadnaviruses, Flaviviruses, Filoviruses, and Arenaviruses. Antimicrob. Agents Chemother. 55, 478-486. doi: 10.1128/AAC.00989-10

Hallegraeff, G. M., Anderson, D. M., and Cembella, A. D. (eds). (2003). Manual on Harmful Marine Microalgae, Vol. 11. Paris: UNESCO, p. 792.
Havaux, M. (1998). Carotenoids as membrane stabilizers in chloroplasts. Trends Plant Sci. 3, 147-151. doi: 10.1016/S1360-1385(98)01200-X

Hörtensteiner, S. (2013). Update on the biochemistry of chlorophyll breakdown. Plant Mol. Biol. 82, 505-517. doi: 10.1007/s11103-012-9940-Z

Inagaki, N., Kinoshita, K., Kagawa, T., Tanaka, A., Ueno, O., Shimada, H., et al. (2015). Phytochrome B mediates the regulation of chlorophyll biosynthesis through transcriptional regulation of $\mathrm{ChlH}$ and GUN4 in rice seedlings. PLoS One 10:e0135408. doi: 10.1371/journal.pone.0135408

Iyer, L. M., Aravind, L., and Koonin, E. V. (2001). Common origin of four diverse families of large eukaryotic DNA viruses. J. Virol. 75, 11720-11734. doi: 10.1128/JVI.75.23.11720-11734.2001

Jongkees, S. A., and Withers, S. G. (2011). Glycoside cleavage by a new mechanism in unsaturated glucuronyl hydrolases. J. Am. Chem. Soc. 133, 19334-19337. doi: $10.1021 /$ ja209067v

Keller, M. D., Bellows, W. K., and Guillard, R. R. L. (1988). Microwave treatment for sterilization of phytoplankton culture media. J. Exp. Mar. Biol. Ecol. 117, 279-283. doi: 10.1016/0022-0981(88)90063-9

Kim, H.-Y., Fomenko, D. E., Yoon, Y.-E., and Gladyshev, V. N. (2006). Catalytic advantages provided by selenocysteine in methionine-S-sulfoxide reductases. Biochemistry 45, 13697-13704. doi: 10.1021/bi0611614

Koonin, E. V., and Yutin, N. (2010). Origin and evolution of eukaryotic large nucleo-cytoplasmic DNA viruses. Intervirology 53, 284-292. doi: 10.1159/ 000312913

Labunskyy, V. M., Hatfield, D. L., and Gladyshev, V. N. (2014). Selenoproteins: molecular pathways and physiological roles. Physiol. Rev. 94, 739-777. doi: 10.1152/physrev.00039.2013

Labunskyy, V. M., Yoo, M. H., Hatfield, D. L., and Gladyshev, V. N. (2009). Sep15, a thioredoxin-like selenoprotein, is involved in the unfolded protein response and differentially regulated by adaptive and acute ER stresses. Biochemistry 48 , 8458-8465. doi: 10.1021/bi900717p

Lang, A. S., Rise, M. L., Culley, A. I., and Steward, G. F. (2009). RNA viruses in the sea. FEMS Microbiol. Rev. 33, 295-323. doi: 10.1111/j.1574-6976.2008. 00132.x

Lazard, M., Blanquet, S., Fisicaro, P., Labarraque, G., and Plateau, P. (2010). Uptake of selenite by Saccharomyces cerevisiae involves the high and low affinity orthophosphate transporters. J. Biol. Chem. 285, 32029-32037. doi: 10.1074/jbc. M110.139865

Legendre, M., Audic, S., Poirot, O., Hingamp, P., Seltzer, V., Byrne, D., et al. (2010). mRNA deep sequencing reveals 75 new genes and a complex transcriptional landscape in Mimivirus. Genome Res. 20, 664-674. doi: 10.1101/gr.102 582.109

Liang, T. J. (2009). Hepatitis B: the virus and disease. Hepatology 49, S13-S21. doi: $10.1002 /$ hep. 22881

Luo, W., Friedman, M. S., Shedden, K., Hankenson, K. D., and Woolf, P. J. (2009). GAGE: generally applicable gene set enrichment for pathway analysis. BMC Bioinformatics 10:161. doi: 10.1186/1471-2105-10-161

Maat, D. S., Crawfurd, K. J., Timmermans, K. R., and Brussaard, C. P. D. (2014) Elevated CO2 and phosphate limitation favor Micromonas pusilla through stimulated growth and reduced viral impact. Appl. Environ. Microbiol. 80, 3119-3127. doi: 10.1128/AEM.03639-13

Maere, S., Heymans, K., and Kuiper, M. (2005). BiNGO: a Cytoscape plugin to assess overrepresentation of Gene Ontology categories in biological networks. Bioinformatics 21, 3448-3449. doi: 10.1093/bioinformatics/bti551

Mock, H.-P., Keetman, U., Kruse, E., Rank, B., and Grimm, B. (1998). Defense responses to tetrapyrrole-induced oxidative stress in transgenic plants with reduced uroporphyrinogen decarboxylase or coproporphyrinogen oxidase activity. Plant Physiol. 116, 107-116. doi: 10.1104/pp. 116.1.107

Moniruzzaman, M., Lecleir, G. R., Brown, C. M., Gobler, C. J., Bidle, K. D., and Wilson, W. H. (2014). Genome of brown tide virus (AaV), the little giant of the Megaviridae, elucidates NCLDV genome expansion and host-virus coevolution. Virology 466-467, 60-70. doi: 10.1016/j.virol.2014.06.031

Moniruzzaman, M., Wurch, L. L., Alexander, H., Dyhrman, S. T., Gobler, C. J., and Wilhelm, S. W. (2017). Virus-host relationships of marine singlecelled eukaryotes resolved from metatranscriptomics. Nat. Commun. 8:16054. doi: $10.1038 /$ ncomms 16054

Monnier, A., Liverani, S., Bouvet, R., Jesson, B., Smith, J. Q., Mosser, J., et al. (2010). Orchestrated transcription of biological processes in the marine picoeukaryote 
Ostreococcus exposed to light/dark cycles. BMC Genomics 11:192. doi: 10.1186/ 1471-2164-11-192

Moskovitz, J. (2005). Methionine sulfoxide reductases: ubiquitous enzymes involved in antioxidant defense, protein regulation, and prevention of agingassociated diseases. Biochim. Biophys. Acta 1703, 213-219. doi: 10.1016/j. bbapap.2004.09.003

Noble, R. T., and Fuhrman, J. A. (1998). Use of SYBR Green I for rapid epifluorescence counts of marine viruses and bacteria. Aquat. Microb. Ecol. 14, 113-118. doi: 10.3354/ame014113

Noctor, G., and Foyer, C. H. (1998). Ascorbate and glutathione: keeping active oxygen under control. Annu. Rev. Plant Physiol. Plant Mol. Biol. 49, 249-279. doi: 10.1146/annurev.arplant.49.1.249

Obornik, M., and Green, B. R. (2005). Mosaic origin of the heme biosynthesis pathway in photosynthetic eukaryotes. Mol. Biol. Evol. 22, 2343-2353. doi: $10.1093 / \mathrm{molbev} / \mathrm{msi} 230$

Ogata, H., Ray, J., Toyoda, K., Sandaa, R.-A., Nagasaki, K., Bratbak, G., et al. (2011). Two new subfamilies of DNA mismatch repair proteins (MutS) specifically abundant in the marine environment. ISME J. 5, 1143-1151. doi: 10.1038/ismej. 2010.210

Ong, H. C., Wilhelm, S. W., Gobler, C. J., Bullerjahn, G., Jacobs, M. A., Mckay, J., et al. (2010). Analyses of the complete chloroplast genome sequences of two members of the pelagophyceae: Aureococcus anophagefferens CCMP1984 and Aureoumbra lagunensis CCMP15071. J. Phycol. 46, 602-615. doi: 10.1111/j. 1529-8817.2010.00841.x

Ortmann, A. C., and Suttle, C. A. (2009). Determination of virus abundance by epifluorescence microscopy. Methods Mol. Biol. 501, 87-95. doi: 10.1007/9781-60327-164-6_10

Peñuelas, J., and Munné-Bosch, S. (2005). Isoprenoids: an evolutionary pool for photoprotection. Trends Plant Sci. 10, 166-169. doi: 10.1016/j.tplants.2005. 02.005

Philippe, J., Janice, E. L., Curtis, A. S., and Paul, J. H. (2003). Effects of viral infection on photosynthetic processes in the bloom-forming alga Heterosigma akashiwo. Aquat. Microb. Ecol. 31, 9-17. doi: 10.3354/ame031009

R Core Team (2013). R: A Language and Environment for Statistical Computing. Vienna: R Foundation for Statistical Computing.

Raina, A., Tuomi, K., and Mantyjarvi, R. (1981). Roles of polyamines in the replication of animal viruses. Med. Biol. 59, 428-432.

Raoult, D., Audic, S., Robert, C., Abergel, C., Renesto, P., Ogata, H., et al. (2004). The 1.2-Megabase genome sequence of Mimivirus. Science 306, 1344-1350. doi: 10.1126/science.1101485

Reinbothe, S., Reinbothe, C., Apel, K., and Lebedev, N. (1996). Evolution of chlorophyll biosynthesis-the challenge to survive photooxidation. Cell 86, 703-705. doi: 10.1016/S0092-8674(00)80144-0

Renesto, P., Abergel, C., Decloquement, P., Moinier, D., Azza, S., Ogata, H., et al. (2006). Mimivirus giant particles incorporate a large fraction of anonymous and unique gene products. J. Virol. 80, 11678-11685. doi: 10.1128/JVI. 00940-06

Robinson, M. D., Mccarthy, D. J., and Smyth, G. K. (2010). edgeR: a Bioconductor package for differential expression analysis of digital gene expression data. Bioinformatics 26, 139-140. doi: 10.1093/bioinformatics/btp616

Rodriguez-Boulan, E., and Müsch, A. (2005). Protein sorting in the golgi complex: shifting paradigms. Biochim. Biophys. Acta 1744, 455-464. doi: 10.1016/j. bbamcr.2005.04.007

Roitman, S., Hornung, E., Flores-Uribe, J., Sharon, I., Feussner, I., and Béjà, O. (2017). Cyanophage-encoded lipid desaturases: oceanic distribution, diversity and function. ISME J. 12, 343-355. doi: 10.1038/ismej.2017.159

Rosenwasser, S., Mausz, M. A., Schatz, D., Sheyn, U., Malitsky, S., Aharoni, A., et al. (2014). Rewiring host lipid metabolism by large viruses determines the fate of Emiliania huxley, a bloom-forming alga in the ocean. Plant Cell 26, 2689-2707. doi: $10.1105 /$ tpc.114.125641

Rosenwasser, S., Ziv, C., Creveld, S. G., and Vardi, A. (2016). Virocell metabolism: metabolic innovations during host-virus interactions in the ccean. Trends Microbiol. 24, 821-832. doi: 10.1016/j.tim.2016.06.006

Rowe, J. M., Dunlap, J. R., Gobler, C. J., Anderson, O. R., Gastrich, M. D., and Wilhelm, S. W. (2008). Isolation of a non-phage-like lytic virus infecting Aureococcus anophagefferens. J. Phycol. 44, 71-76. doi: 10.1111/j.1529-8817. 2007.00453.x
Rüdiger, W. (2009). "Regulation of the late steps of chlorophyll biosynthesis," in Tetrapyrroles: Birth, Life and Death, eds M. Warren and A. Smith (New York, NY: Springer), 263-273.

Sanchez, E. L., and Lagunoff, M. (2015). Viral activation of cellular metabolism. Virology 479, 609-618. doi: 10.1016/j.virol.2015.02.038

Santini, S., Jeudy, S., Bartoli, J., Poirot, O., Lescot, M., and Abergel, C. (2013). Genome of Phaeocystis globosa virus PgV-16T highlights the common ancestry of the largest known DNA viruses infecting eukaryotes. Proc. Natl. Acad. Sci. U.S.A. 110, 10800-10805. doi: 10.1073/pnas. 1303251110

Schwarz, K. B. (1996). Oxidative stress during viral infection: a review. Free Radic. Biol. Med. 21, 641-649. doi: 10.1016/0891-5849(96)00131-1

Seaton, G., Lee, K., and Rohozinski, J. (1995). Photosynthetic shutdown in Chlorella NC64A associated with the infection cycle of Paramecium bursaria Chlorella Virus-1. Plant Physiol. 108, 1431-1438. doi: 10.1104/pp.108.4.1431

Sheyn, U., Rosenwasser, S., Ben-Dor, S., Porat, Z., and Vardi, A. (2016). Modulation of host ROS metabolism is essential for viral infection of a bloom-forming Coccolithophore in the ocean. ISME J. 10, 1742-1754. doi: 10.1038/ismej. 2015.228

Short, S. M. (2012). The ecology of viruses that infect eukaryotic algae. Environ. Microbiol. 14, 2253-2271. doi: 10.1111/j.1462-2920.2012.02706.x

Suttle, C. A. (2007). Marine viruses - major players in the global ecosystem. Nat. Rev. Microbiol. 5, 801-812. doi: 10.1038/nrmicrol750

Tan, K.-L., and Board, P. G. (1996). Purification and characterization of a recombinant human Theta-class glutathione transferase (GSTT2-2). Biochem. J. 315, 727-732. doi: 10.1042/bj3150727

Tatusov, R., Galperin, M., Natale, D., and Koonin, E. (2000). The COG database: a tool for genome-scale analysis of protein functions and evolution. Nucleic Acids Res. 28, 33-36. doi: 10.1093/nar/28.1.33

Taylor, E. W., Nadimpalli, R. G., and Ramanathan, C. S. (1997). Genomic structures of viral agents in relation to the biosynthesis of selenoproteins. Biol. Trace Elem. Res. 56, 63-91. doi: 10.1007/BF02778984

Thiagarajan, V., Byrdin, M., Eker, A. P., Müller, P., and Brettel, K. (2011). Kinetics of cyclobutane thymine dimer splitting by DNA photolyase directly monitored in the UV. Proc. Natl. Acad. Sci. U.S.A. 108, 9402-9407. doi: 10.1073/pnas. 1101026108

Ursini, F., Maiorino, M., Brigelius-Flohe, R., Aumann, K. D., Roveri, A., Schomburg, D., et al. (1995). Diversity of glutathione peroxidases. Methods Enzymol. 252, 38-53. doi: 10.1016/0076-6879(95)52007-4

Vardi, A., Haramaty, L., Van Mooy, B. A., Fredricks, H. F., Kimmance, S. A., Larsen, A., et al. (2012). Host-virus dynamics and subcellular controls of cell fate in a natural Coccolithophore population. Proc. Natl. Acad. Sci. U.S.A. 109, 19327-19332. doi: 10.1073/pnas.1208895109

Vardi, A., Van Mooy, B. A. S., Fredricks, H. F., Popendorf, K. J., Ossolinski, J. E., Haramaty, L., et al. (2009). Viral glycosphingolipids induce lytic infection and cell death in marine phytoplankton. Science 326, 861-865. doi: 10.1126/science. 1177322

Veal, E. A., Toone, W. M., Jones, N., and Morgan, B. A. (2002). Distinct roles for glutathione S-transferases in the oxidative stress response in Schizosaccharomyces pombe. J. Biol. Chem. 277, 35523-35531. doi: 10.1074/jbc. M111548200

Vestal, D. J., and Jeyaratnam, J. A. (2011). The guanylate-binding proteins: emerging insights into the biochemical properties and functions of this family of large interferon-induced guanosine triphosphatase. J. Interferon Cytokine Res. 31, 89-97. doi: $10.1089 /$ jir.2010.0102

Weinbauer, M. G., Wilhelm, S. W., Suttle, C. A., and Garza, D. R. (1997). Photoreactivation compensates for UV damage and restores infectivity to natural marine virus communities. Appl. Environ. Microbiol. 63, 2200-2205.

Wilhelm, S. W., Bird, J. T., Bonifer, K. S., Calfee, B. C., Chen, T., Coy, S. R., et al. (2017). A student's guide to giant viruses infecting small eukaryotes: from Acanthamoeba to Zooxanthellae. Viruses 9:E46. doi: 10.3390/v9030046

Wilhelm, S. W., Coy, S. R., Gann, E. R., Moniruzzaman, M., and Stough, J. M. A. (2016). Standing on the shoulders of giant viruses: five lessons learned about large viruses infecting small eukaryotes and the opportunities they create. PLoS Pathog. 12:e1005752. doi: 10.1371/journal.ppat.1005752

Wilhelm, S. W., and Suttle, C. A. (1999). Viruses and nutrient cycles in the sea: viruses play critical roles in the structure and function of aquatic food webs. Bioscience 49, 781-788. doi: 10.2307/1313569 
Wilson, W. H., Gilg, I. C., Duarte, A., and Ogata, H. (2014). Development of DNA mismatch repair gene, MutS, as a diagnostic marker for detection and phylogenetic analysis of algal Megaviruses. Virology 466-467, 123-128. doi: 10.1016/j.virol.2014.07.001

Wilson, W. H., Schroeder, D. C., Allen, M. J., Holden, M. T. G., Parkhill, J., Barrell, B. G., et al. (2005). Complete genome sequence and lytic phase transcription profile of a Coccolithovirus. Science 309, 1090-1092. doi: 10.1126/science. 1113109

Yutin, N., Wolf, Y., Raoult, D., and Koonin, E. (2009). Eukaryotic large nucleocytoplasmic DNA viruses: clusters of orthologous genes and reconstruction of viral genome evolution. Virol. J. 6:223. doi: 10.1186/1743-422X6-223

Zhao, L., Cox, A. G., Ruzicka, J. A., Bhat, A. A., Zhang, W., and Taylor, E. W. (2000). Molecular modeling and in vitro activity of an HIV-1-encoded glutathione peroxidase. Proc. Natl. Acad. Sci. U.S.A. 97, 6356-6361. doi: 10.1073/pnas.97. 12.6356

Conflict of Interest Statement: The authors declare that the research was conducted in the absence of any commercial or financial relationships that could be construed as a potential conflict of interest.

Copyright (C) 2018 Moniruzzaman, Gann and Wilhelm. This is an open-access article distributed under the terms of the Creative Commons Attribution License (CC BY). The use, distribution or reproduction in other forums is permitted, provided the original author(s) and the copyright owner are credited and that the original publication in this journal is cited, in accordance with accepted academic practice. No use, distribution or reproduction is permitted which does not comply with these terms. 